Research Article

\title{
Experimental Study on Influencing Factors of Characteristic Index of Local Horizontal Frozen Body of Double-Row Pipe under Seepage
}

\author{
Renliang Shan, Weijun Liu (D, Gaojun Chai, and Shengchao Xiao \\ College of Mechanics and Construction Engineering, China University of Mining and Technology (Beijing), Beijing 100083, China \\ Correspondence should be addressed to Weijun Liu; 1615541146@qq.com
}

Received 17 January 2020; Accepted 3 March 2020; Published 1 April 2020

Academic Editor: Sakar Mohan

Copyright (c) 2020 Renliang Shan et al. This is an open access article distributed under the Creative Commons Attribution License, which permits unrestricted use, distribution, and reproduction in any medium, provided the original work is properly cited.

\begin{abstract}
In order to deeply understand the influence of different factors on the characteristic indicators of the double-row-pipe partial horizontal frozen body in the sand-gravel stratum under the effect of seepage flow, several sets of sand-gravel stratum frozen model tests were carried out based on the similarity theory. The research showed that (1) under the effect of seepage flow, the backwater surface of the horizontal frozen body is in the shape of a quadratic parabolic and the development velocity of the backwater surface is inversely proportional to the square of the freezing time. The influence of seepage velocity on the downstream length and the freezing front development velocity of the backwater surface is stronger than the refrigerant temperature; (2) overlap time of the second row of frozen soil column increases with the increase of the distance between frozen pipes and seepage velocity and decreases with the decrease of the refrigerant temperature. The influence of various factors on the overlap time follows the order as the distance between freezing pipes $>$ seepage velocity > refrigerant temperature. The average development velocity of the upstream surface decreases with the increase of the seepage velocity and the refrigerant temperature and first increases and then decreases with the increase of freezing pipe spacing. The influence of various factors on the average development velocity follows the order as seepage velocity $>$ the distance between freezing pipes $>$ refrigerant temperature. In addition, through the regression analysis, the quantitative relationship between the maximum arrangement spacing of the frozen pipes, the seepage velocity, and the refrigerant temperature was obtained. The research results can provide a basis for large-area partial horizontal freezing construction in Beijing sand-gravel stratum.
\end{abstract}

\section{Introduction}

Freezing technology is a construction technique that sends refrigerant into the stratum to form an impervious structure by freezing the water [1]. Because of its adaptability to complex stratum, good water-sealing ability, no pollution, technical maturity, and reliability, it has been widely used in construction [2-5]. The effects of different factors such as seepage velocity, distance between freezing pipes, refrigerant temperature, and diameter of the frozen pipe were studied by Zhou et al. [6]. It was concluded that the distance between freezing pipes is the primary factor to influence the frozen soil column overlap; however, the interaction between various factors was not summarized. A coupled thermohydraulic finite model of frozen soil with an optimization algorithm combined with ant colony was proposed by Marwan et al. [1]. After verifying the model through experimental data, the optimal placement of frozen pipes was obtained. Based on the Bakholdin formula, $\mathrm{Hu}$ and $\mathrm{He}[7,8]$ derived the equivalent trapezoidal algorithm to calculate the average temperature of the double-row-pipe or even the multirow-pipe frozen wall. Based on the potential superposition theory, multipipe steady-state freezing temperature field was achieved. According to the boundary separability of the harmonic equation, the straight linear arrangement model can be decomposed into two special single-row-pipe freezing problems, and the temperature field analytical solution to the generalized circular double-loop pipe is thus obtained [9]. Wang et al. [10] simulated the artificial shaft freezing process under the effect of large-flow groundwater 
by using the numerical calculation model and concluded that the artificial freezing temperature field is significantly affected when the flow velocity is greater than $5 \mathrm{~m} / \mathrm{d}$. Lai et al. [11] deduced the governing differential equations for the coupling problem of phase transition temperature field and seepage field. Then, the finite element calculation formula of the problem was obtained by the Galerkin method. Yang and Pi [12] simulated the single-pipe freezing process by numerical simulation and obtained the quantitative relationship between the maximum arrangement spacing of the frozen pipe and the thermal conductivity of the stratum and the temperature of the outer wall surface of the frozen pipe and other factors. The simulation correctness was verified by the measurement data by Lin et al. [13]; then, the influence of seepage velocity on the frozen wall formation was analyzed by numerical simulation. Pimentel et al. [14] simulated the formation process of single-row-pipe frozen wall under high seepage velocity through large-scale physical model test and compared test results with the existing artificial ground freezing closed-form solution.

Until now, a lot of research studies have been performed on the stratum freezing technology [1, 6-19], but some limitations still exist. Firstly, when they are used to study the development law of the frozen wall under the seepage, most of the model tests are the single-row-pipe frozen one. The development laws of the temperature fields of the singlerow-pipe, double-row-pipe, and even multitube-pipe frozen wall under the effect of seepage flow are significantly different from each other. Secondly, the frozen pipes are fulllength freezing, which is significantly different from the partial freezing technique in temperature field under the effect of seepage flow. In addition, the model test mostly uses homogeneous sand as the soil heat transfer medium, but rarely uses sand gravel. In order to understand the effects of various factors such as the seepage velocity, distance between freezing pipes, and refrigerant temperature on the characteristic indexes of the horizontal frozen body, multiple groups of model test were also applied in sand-gravel stratum. The research results can provide a basis for largearea partial freezing construction in Beijing sand-gravel stratum (Beijing has been marked with a red star in the map of China in Figure 1).

\section{Test Design}

2.1. Test Equipment and Similarity Theory. Based on the principle of energy conservation and Darcy's law in porous media, the coupled equation of water and heat in freezing process can be written as follows:

$$
\begin{aligned}
C_{\mathrm{eq}} \frac{\partial T}{\partial t} & =\nabla\left(\lambda_{\mathrm{eq}} \nabla T\right)-\rho_{w} C_{w} \vec{u} \nabla T+L \rho_{i} \frac{\partial \theta_{i}}{\partial t}, \\
\mu_{s} \frac{\partial H_{p}}{\partial t} & =\nabla(K(T) \nabla H),
\end{aligned}
$$

where $C_{w}$ represents the hydrothermal capacity; $C_{\mathrm{eq}}$ denotes the equivalent volume heat capacity $\left(\mathrm{kJ} /\left(\mathrm{m}^{3} \cdot{ }^{\circ} \mathrm{C}\right)\right) ; \lambda_{\text {eq }}$ indicates the equivalent thermal conductivity $\left(\mathrm{kJ} /\left(\mathrm{m} \cdot \mathrm{s} \cdot{ }^{\circ} \mathrm{C}\right)\right) ; \rho_{w}$ and $\rho_{i}$ are water density and ice density, respectively $\left(\mathrm{kg} / \mathrm{m}^{3}\right)$;
$L$ represents latent heat $\left(\mathrm{kJ} / \mathrm{m}^{3}\right) ; T$ is soil temperature $\left({ }^{\circ} \mathrm{C}\right) ; t$ denotes freezing time $(s) ; \vec{u}$ indicates seepage velocity vector $(\mathrm{m} / \mathrm{d}) ; \mu_{s}$ represents specific storativity; $H_{p}$ is waterhead $(m)$; and $K(T)$ denotes permeability coefficient $(\mathrm{m} / \mathrm{d})$.

If the porosity of soil is $\theta_{s}$ and the content of water and ice in the pores is $\theta_{w}$ and $\theta_{i}$, respectively, then

$$
\begin{aligned}
& C_{\mathrm{eq}}=\theta_{s} \rho_{s} C_{s}+\theta_{w} \rho_{w} C_{w}+\theta_{i} \rho_{i} C_{i}, \\
& \lambda_{\mathrm{eq}}=\theta_{s} \lambda_{s}+\theta_{w} \lambda_{w}+\theta_{i} \lambda_{i},
\end{aligned}
$$

where $\lambda_{s}, \lambda_{w}$, and $\lambda_{i}$ represent the thermal conductivity of soil particles, water, and ice.

In the process of freezing, the soil temperature Tnot only affects the content of water and ice in the pores but also blocks the original pore passage due to the formation of ice. Therefore, the permeability coefficient $K(T)$ is also a variable affected by the temperature.

2.2. Test Equipment and Similarity Theory. Figure 2 shows a schematic diagram of the test device. The seepage velocity was controlled by the pump pressure, and the refrigerant at the set temperature was outputted by the refrigeration compressor. Moreover, the local frozen sections of the tworow pipe were considered as the freezing system.

The diameter of the frozen pipes was $16 \mathrm{~mm}$, which simulated the diameter of $159 \mathrm{~mm}$ in the project. The geometrical reduction ratio $C_{d}$ is 10 . List $\pi$ terms and similarity criterion according to dimensions, the physical property similarity ratio of all materials is 1 $\left(C_{\alpha s p}=C_{\lambda}=C_{B}=1\right)$. Meanwhile, the temperature reduction ratio $C_{T}=1$, the time reduction ratio $C_{\mathrm{t}}=C_{d}^{2}=100$, and the seepage velocity reduction velocity $C_{\mathrm{v}}=1 / C_{d}=1 / 10$. The sand-gravel soil for test was taken from the construction site. The physical parameters are as follows: particle density of $2.499 \mathrm{~g} / \mathrm{cm}^{3}$, saturated water content of $2.7 \%$, and porosity of 18.57 .

2.3. Measuring Point Arrangement. The layout diagram of the frozen pipe and the temperature measuring point is shown in Figures 2 and 3. In Figure 3, S means the spacing between the freezing pipes, and the unit standard of measurement is $\mathrm{mm}$. A total of two rows and four columns of frozen pipes were arranged. Only $0.32 \mathrm{~m}$ in the middle was a local frozen section, and nonfrozen sections were insulated by thermal insulation cotton. 36 temperature measuring points were arranged. In this test, the platinum resistance PT100 was used to measure the temperature of the measuring point with a measurement accuracy of $0.1^{\circ} \mathrm{C}$. When the temperature of the measuring point was below $0^{\circ} \mathrm{C}$, it was considered that the frozen front had expanded to the location of the measuring point.

2.4. Experimental Program. According to previous research studies $[6,19]$, the horizontal frozen body formation process under the effect of seepage can be divided into three stages. Firstly, the second row (last row) of the frozen soil column overlapped. Secondly, the first row of the frozen soil column 


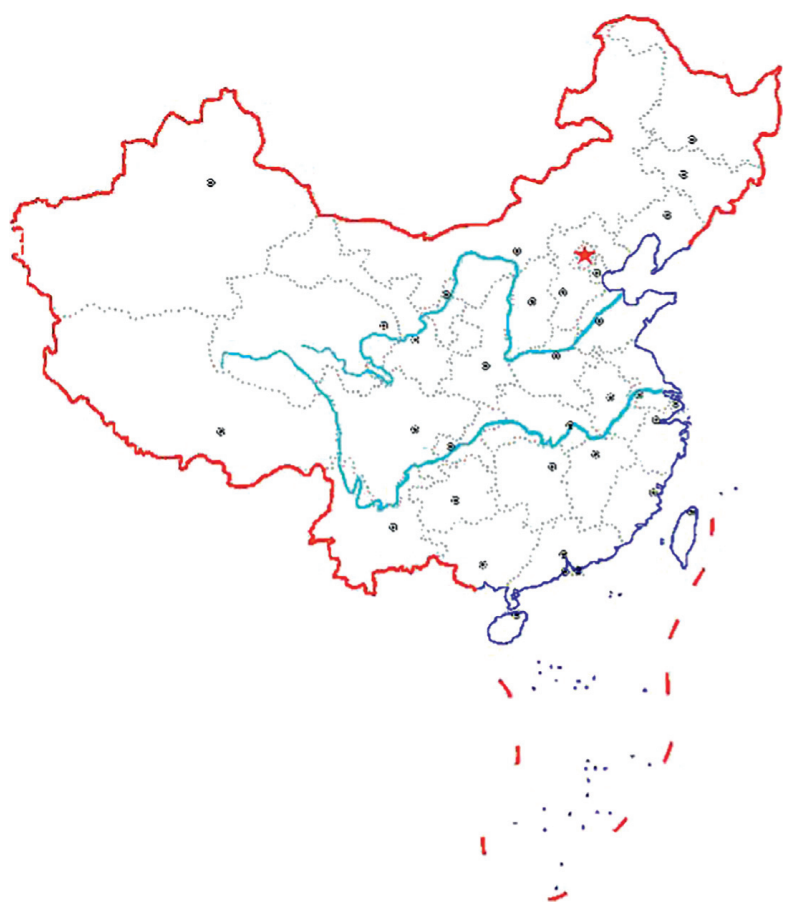

Figure 1: Location of Beijing (from the Internet).

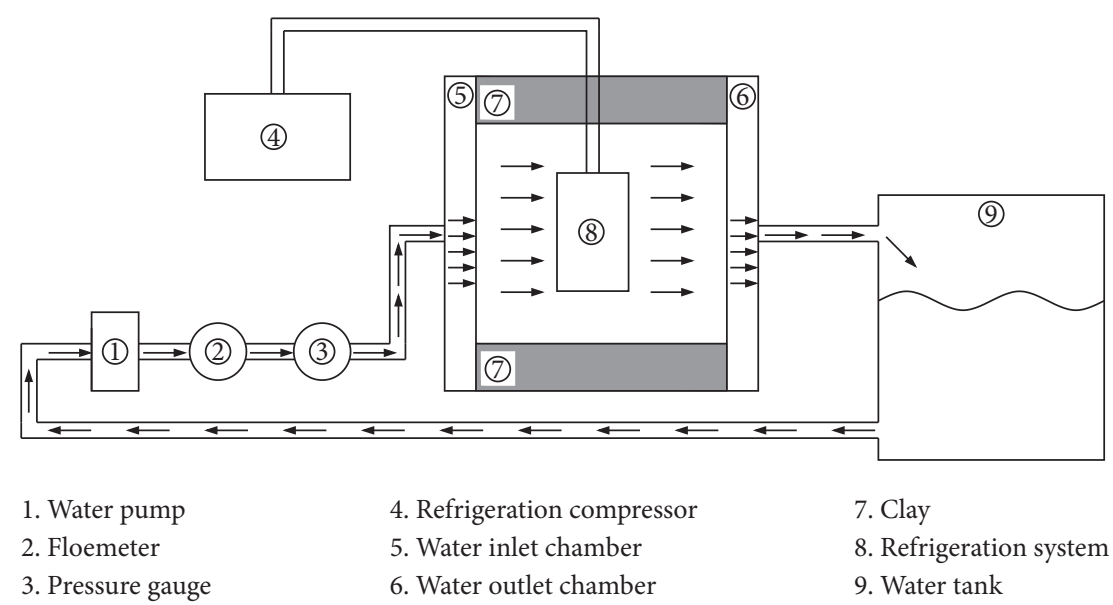

Figure 2: Schematic diagram of the freezing model test system.

overlapped and formed a continuous horizontal frozen body; meanwhile, the backwater surface developed. Thirdly, the upper water surface continued to develop. While the distance between freezing pipes $S$, seepage velocity $u$, and refrigerant temperature $T_{c}$ are important factors to affect the development law of the frozen wall. All the test factors and corresponding levels are shown in Table 1. For ease of analysis, all of the test results below have been normalized according to similarity theory.

Under hydrostatic conditions, the radius of the cooling zone is generally 3 to 5 times the thickness of the outer side of the frozen column [6]. The maximum distance of the frozen pipe in the model test is $140 \mathrm{~mm}$, and the radius of the cooling zone is about $297 \mathrm{~mm}$. Meanwhile, the distance between the frozen pipe and boundary of both sides is $390 \mathrm{~mm}$. Given the inhibition effect of seepage water on the development of temperature field, the range of cooling zone is reduced.

\section{Result Analysis}

As shown in Figure 4, the length of the horizontal frozen body along the flow direction can be divided into three parts: upstream length along the flow direction (hereinafter, referred to as upstream length $E_{u}$ ), middle length along the flow direction (hereinafter, referred to as middle length $E_{m}$ ), and downstream length along the flow direction (hereinafter, referred to as downstream length $E_{d}$ ). This paper focuses on the influence of variable factors on the characteristic index of the horizontal frozen body, such as the length of downstream flow and the time of intersection 


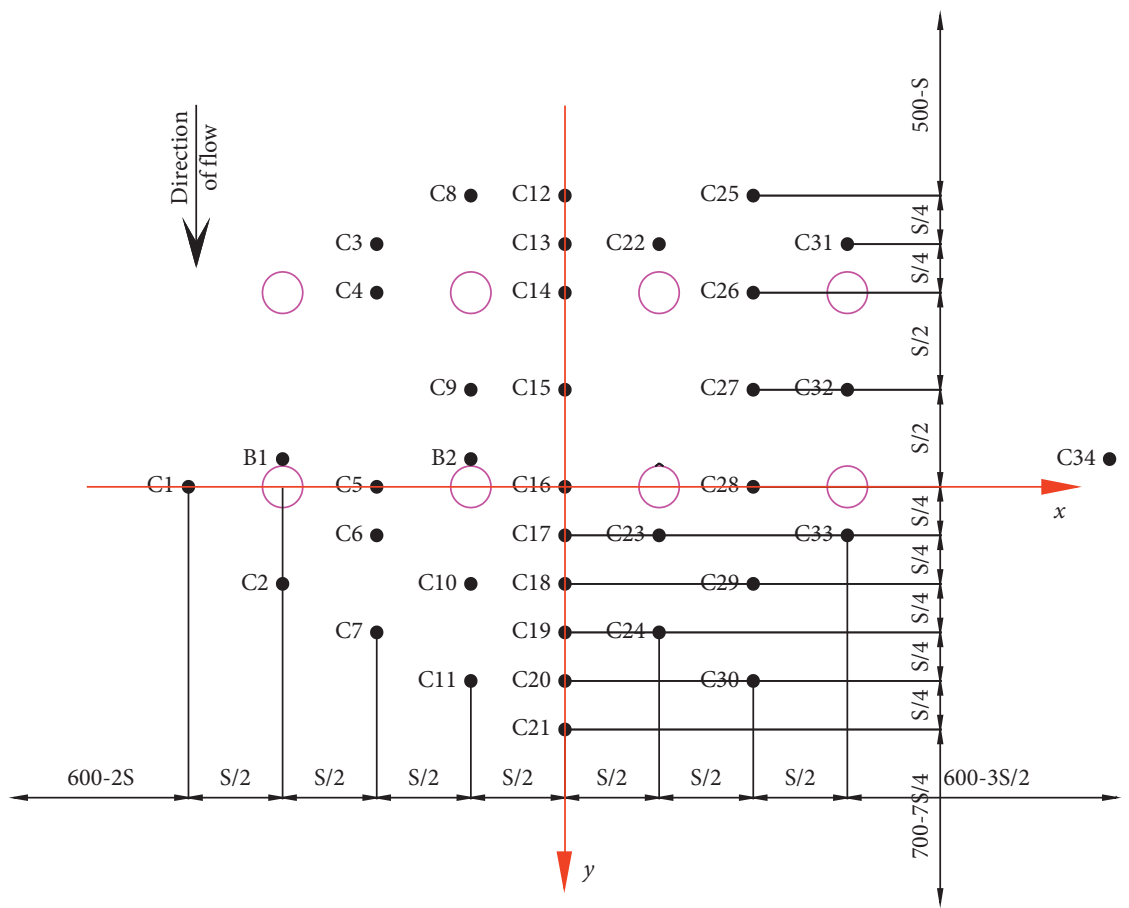

Figure 3: Model design diagram.

TABLE 1: Test table.

\begin{tabular}{lccc}
\hline Test level & $S(\mathrm{~m})$ & $U(\mathrm{~m}) \cdot \mathrm{d}^{-1}$ & $T_{\mathrm{c}}\left({ }^{\circ} \mathrm{C}\right)$ \\
\hline 1 & 0.08 & 5 & -25 \\
2 & 0.10 & 10 & -27 \\
3 & 0.14 & 15 & -29 \\
4 & & 20 & \\
\hline
\end{tabular}

(or the expansion speed of frozen front). Among them, the upstream length $E_{u}$ is short due to the influence of seepage water, which is not analyzed in this paper.

3.1. $E_{d}$. Figure 5 shows the temperature field distribution at the distance between frozen pipes of $0.8 \mathrm{~m}$, the seepage velocity of $1 \mathrm{~m} / \mathrm{d}$, and the freezing temperature of $-25^{\circ} \mathrm{C}$ for $40 \mathrm{~d}$ (unit: ${ }^{\circ} \mathrm{C}$ ).

It was observed in Figure 5 that, in the late stage of freezing, the backwater surface is in the shape of arc. After many attempts and fitting by the author, it is considered that the downstream length has a quadratic parabola relationship with the $x$-axis (the coordinate axis is shown in Figure 2):

$$
E_{d}=A(t) x^{2}+B(t) .
$$

Among them, $A(t)$ and $B(t)$ are approximately inversely proportional to the freezing time $t$, that is,

$$
\begin{aligned}
& A(t)=\frac{C}{t}+D, \\
& B(t)=\frac{E}{t}+F,
\end{aligned}
$$

where $C, D, E$, and $F$ are related to the distance between freezing pipes $S$, the seepage velocity $u$, and the refrigerant temperature $T_{c}$. In the actual project, the length $E_{w}$ along the water surface direction of the horizontal frozen body was fixed, while this experiment was arranged with two rows and four columns of frozen pipes, and the length $E_{w}$ along the water surface direction was not fixed. Therefore, the influences of the seepage velocity $u$ and the refrigerant temperature $T_{\mathrm{c}}$ on $E_{d}$ were only analyzed by the test results of the freezing pipe spacing of $0.8 \mathrm{~m}$. The influence of the freezing pipe spacing on the backwater surface is not considered, so the parameters can be obtained as follows:

$$
\begin{aligned}
C & =c\left(u, T_{c}\right), \\
D & =d\left(u, T_{c}\right), \\
E & =e\left(u, T_{c}\right), \\
F & =f\left(u, T_{c}\right), \\
E_{d} & =\left(\frac{C}{t}+D\right) x^{2}+\left(\frac{E}{t}+F\right) .
\end{aligned}
$$

When $t \longrightarrow \infty$, the downstream limit length is obtained as $E_{\text {dlim }}=D x^{2}+F$, while $\bar{E}_{d \text { lim }}$ was obtained by dividing $3 S$ after $[-3 S / 2,3 S / 2]$ integration. 


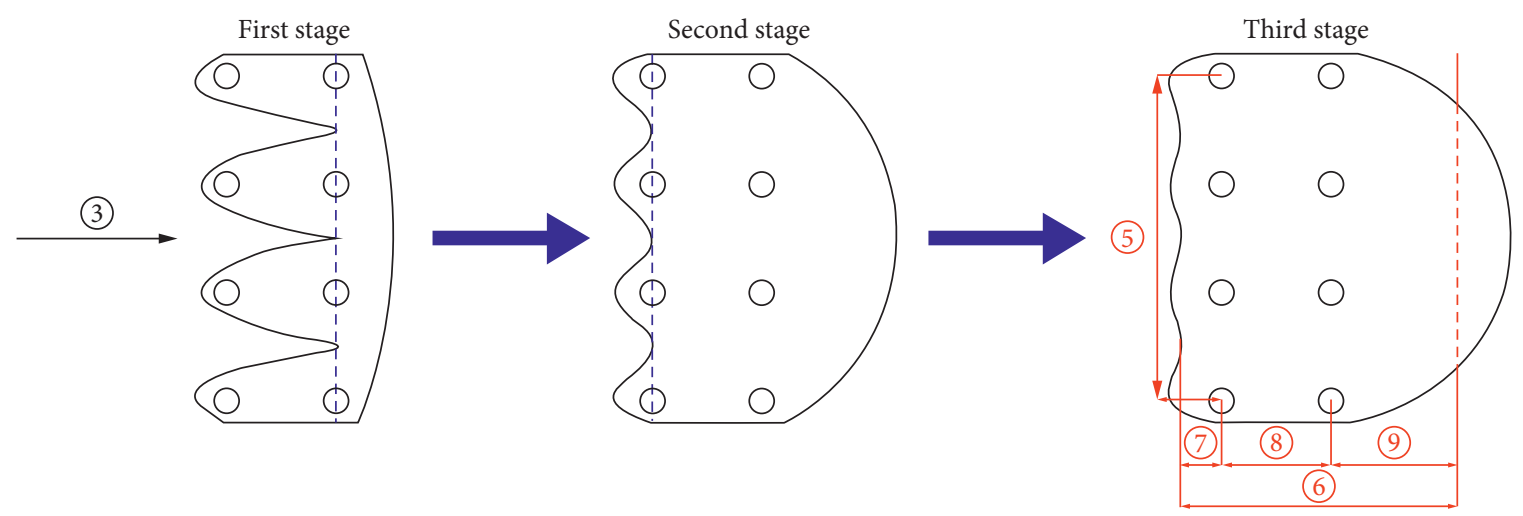

(a)

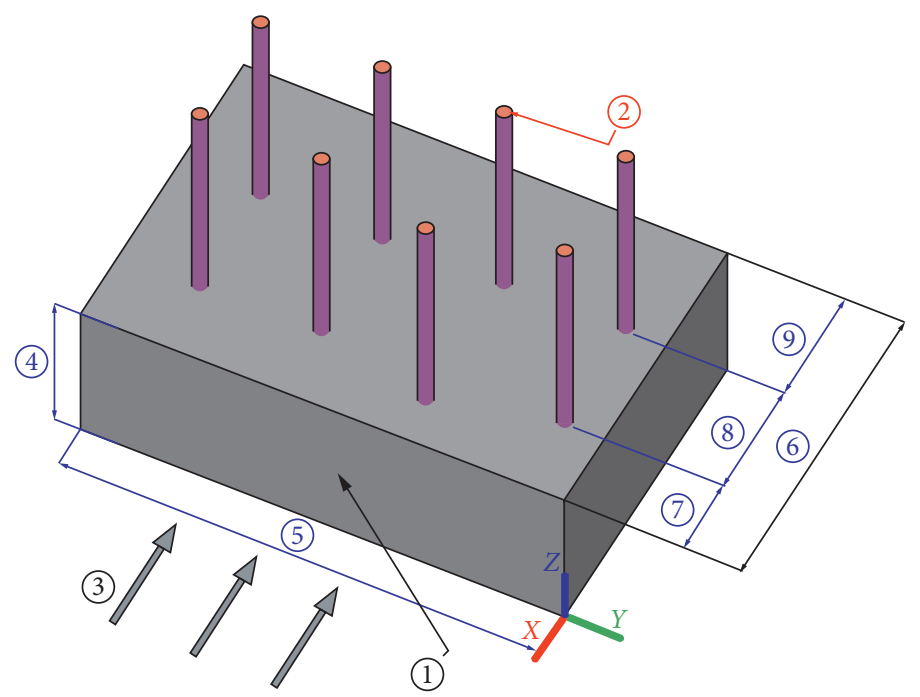

1. Local horizontal frozen body

2. Frozen pipe

3. Direction of flow

4. Thickness

5. Length in water surface direction $E_{w}$

6. Length along the flow direction $E_{f}$

7. Upstream length along the flow direction $E_{u}$ (Abbreviation: upstream length)

8. Middle length along the flow direction $E_{m}$

(Abbreviation: middle length)

9. Downstream length along the flow direction $E_{d}$

(Abbreviation: downstream length)

(b)

Figure 4: Schematic diagram of the horizontal frozen body. (a) Parameters of each stage. (b) Schematic diagram of horizontal frozen body [19].

In this paper, typical test results were selected to characterize the influence of various factors on the downstream limit average length $\overline{E_{d}}$ lim and the quadratic coefficient $D$, as shown in Figure 6.

It was revealed from Figure 6 that the refrigerant temperature $T_{c}$ was approximately proportional to the downstream limit length in the test range. When the seepage velocity is small, the change of the seepage velocity has a significant effect on $\bar{E}_{d \mathrm{lim}}$. As the seepage velocity $u$ increases, the refrigerant temperature $T_{c}$ increases, but the downstream limit average length $\overline{E_{d}}$ lim decreases. Similarly, the larger the seepage velocity $u$, the lower the refrigerant temperature $T_{c}$, the smaller the absolute value of the quadratic coefficient $D$, and the flatter the backwater surface.

In order to analyze the influence of different factors on each characteristic index of the horizontal frozen body, the range method was used in this paper. The range calculation results of $\overline{E_{d}}$ lim are shown in Table 2 . It showed that the influence of the seepage velocity $u$ on the downstream limit 


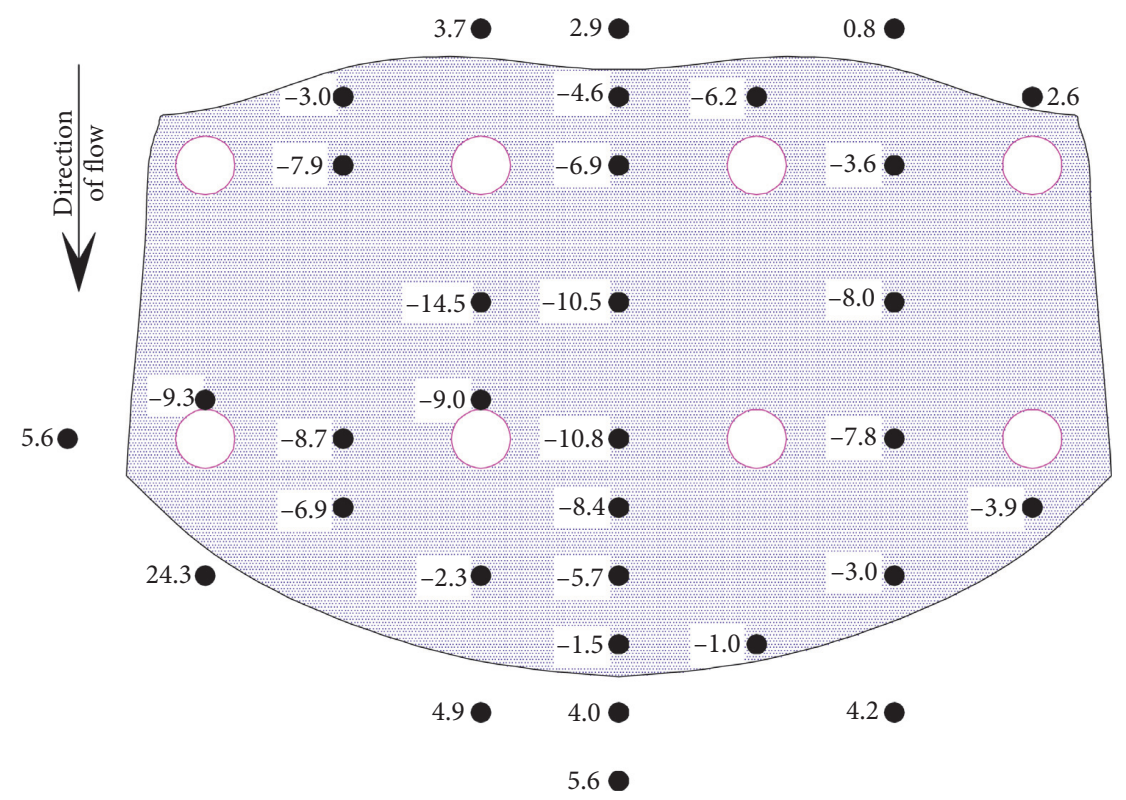

FIGURE 5: Schematic diagram of temperature field distribution.

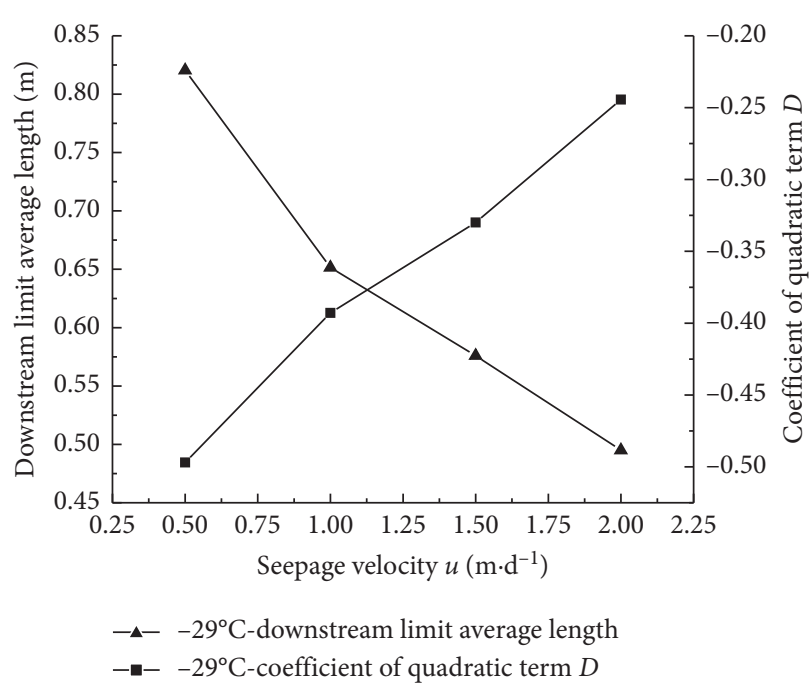

(a)

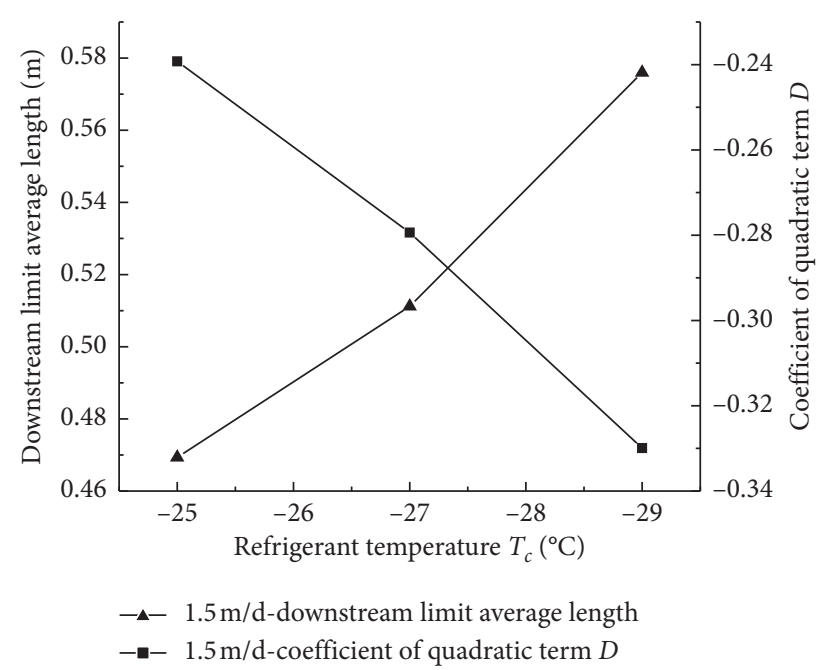

(b)

FIGURE 6: Influences of various factors on downstream length. (a) Seepage velocity $u$ vs. downstream length $E_{d}$. (b) Refrigerant temperature $T_{c}$ vs. downstream length $E_{d}$.

TABLE 2: Calculation of range of $\overline{E_{d}}$ lim.

\begin{tabular}{lcc}
\hline & $\begin{array}{c}\text { Seepage velocity } \\
u\end{array}$ & $\begin{array}{c}\text { Refrigerant temperature } \\
T_{\mathrm{c}}\end{array}$ \\
\hline $\begin{array}{l}\text { Range calculation } \\
(\mathrm{m})\end{array}$ & 0.41 & 0.11 \\
\hline
\end{tabular}

average length $E_{\mathrm{dlim}}$ was greater than the refrigerant temperature $T_{c}$.

3.2. $t_{e}$. Typical test results were selected to characterize the influence of various factors on overlap time $t_{e}$ of the second row of permafrost columns, as shown in Figure 7.
For the comprehensive regression of each parameter, the equation of $t_{\mathrm{e}}$ is as follows:

$$
\begin{aligned}
t_{e} & =111.44\left(-T_{c}\right)^{-1.36} \exp \left(1.37 S^{2} \times u^{0.2}\right)+2.12, \\
R^{2} & =0.977 .
\end{aligned}
$$

As mentioned above, the range method was used for both the calculation and analysis. Table 3 shows the results of the range calculation of each factor for $t_{e}$.

It can be seen from Table 3 that the primary factor to affect $t_{e}$ was the distance between frozen pipes $S$, followed by the seepage velocity $u$, and finally the refrigerant temperature $T_{c}$. Therefore, when the frozen soil column does not 


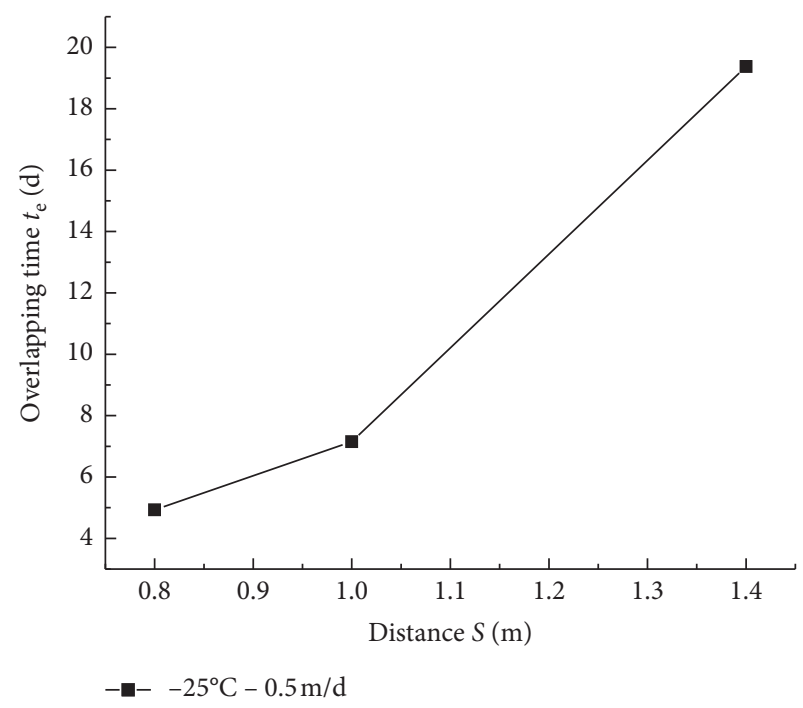

(a)

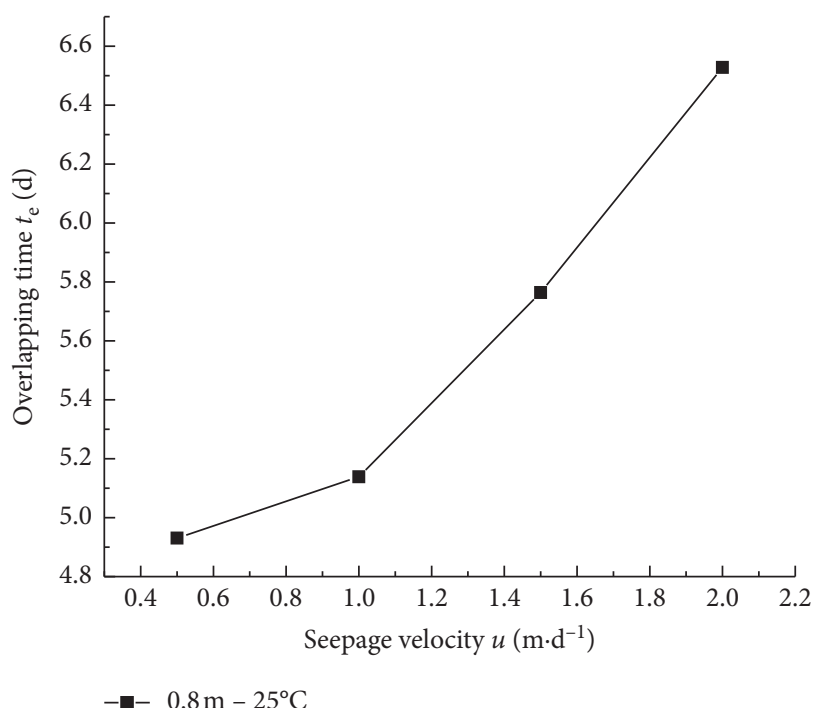

(b)

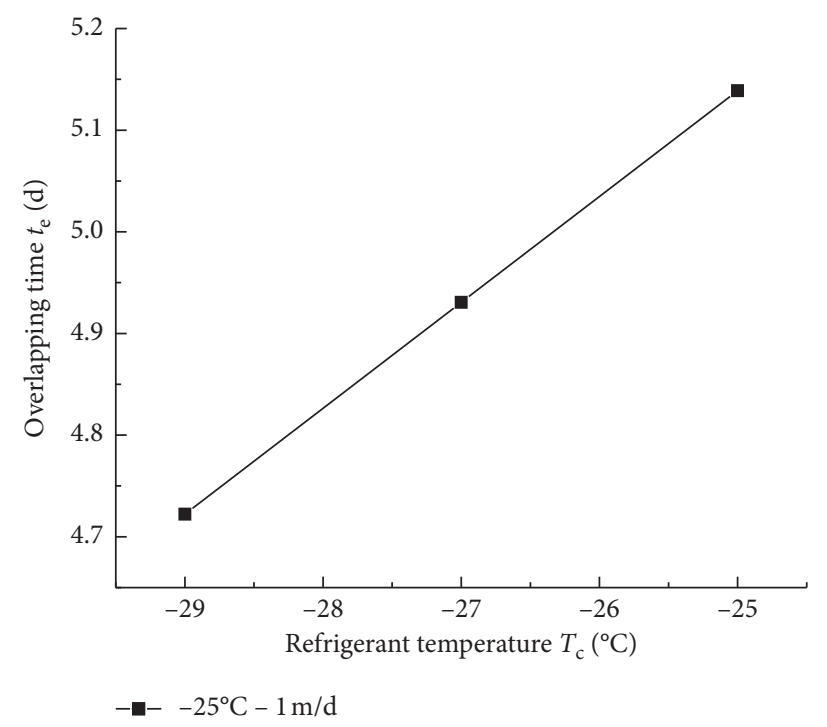

(c)

Figure 7: Curves of the effect of various factors on $\mathrm{t}_{e}$. (a) Distance between frozen pipes $S$ vs. $t_{e}$. (b) Seepage velocity $u$ vs. $t_{e}$. (c) Refrigerant temperature $T_{c}$ vs. $t_{e}$.

TABLE 3: Calculation of variance of $t_{e}$.

\begin{tabular}{lccc}
\hline & $S$ & $u$ & $T_{c}$ \\
\hline Range calculation (d) & 16.6 & 4.4 & 2.4 \\
\hline
\end{tabular}

overlap or the freezing formation time is too long, it is recommended to shorten the spacing of the frozen pipe firstly. Then, it is the second choice to reduce the groundwater seepage velocity by means of grouting, and finally to reduce the temperature of the refrigerant will be considered.

In the actual project, when the overlap time exceeds $50 \mathrm{~d}$, it can be considered that the frozen soil column does not overlap. $t_{e}=50 \mathrm{~d}$ is brought into formula (4); thereby, the maximum distance of the frozen pipe can be obtained as below:

$$
S_{\max }=\sqrt{\frac{\ln \left(-T_{c}\right)-0.61}{u^{0.2}}}, \quad u>0, T_{c}<0
$$

Figure 8 shows the relationship between $S_{\max }$ and $u, T_{c}$. It can be seen from Figure 8 and formula (5) that $S_{\max }$ decreased with the increase of both seepage velocity $u$ and refrigerant temperature $T_{c}$, respectively. However, with the increase of seepage velocity $u$, the decrease rate of $S_{\max }$ tends to be gentle. It is known from Section 3.2 that the influence of the seepage velocity $u$ on $t_{e}$ is greater than the refrigerant temperature $T_{\mathcal{c}}$, and then it was postulated that the primary factor to affect $S_{\max }$ is the seepage velocity $u$, followed by the refrigerant temperature $T_{\mathrm{c}}$. Therefore, basic tests such as groundwater seepage velocity and soil porosity test should 


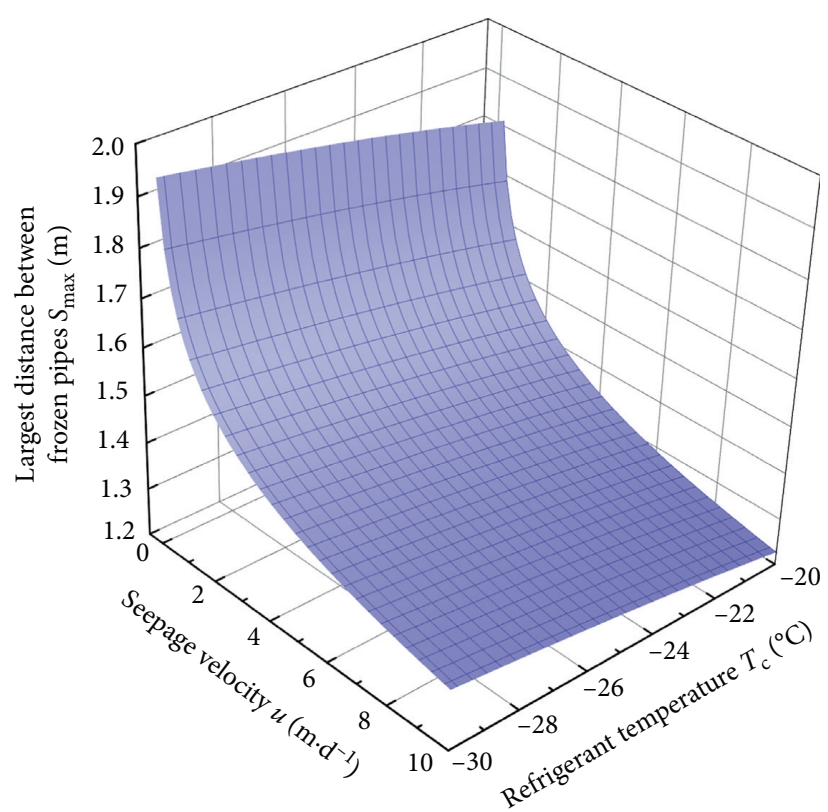

FIgURE 8: The relation diagram of $S_{\max }$ with $u$ and $T_{c}$.

be performed in the actual project to provide the basis for the rational design of the freezing project.

3.3. $v_{m}$. The average development velocity $v_{m}$ of the freezing front of the water surface is one of the important characteristic index of the horizontal frozen body:

$$
v_{m}=\frac{S}{t_{m}}
$$

where $t_{m}$ is the time from the intersection of the second row of permafrost columns to the formation of continuous horizontal frozen body (that is, the overlap time of the first row of permafrost columns minus the overlap time of the second row of permafrost columns). Similarly, some typical test results were selected to characterize the influence of various factors on $v_{m}$, as shown in Figure 9.

It was demonstrated in Figure 9 that $v_{m}$ decreased with the increase of both $u$ and $T_{c}$, respectively. In addition, $v_{m}$ increased first and then decreased with $S$.

As mentioned above, the range method was used for calculation and analysis. Table 4 shows the results of the range calculation of each factor for $v_{m}$. The influences of various factors on $v_{m}$ were as follows: seepage velocity $u>$ the distance between freezing pipes $S>$ refrigerant temperature $T_{c}$.

3.4. $v_{d}$. In this paper, the influence of the seepage velocity $u$ and the refrigerant temperature $T_{c}$ on the development velocity $v_{d}$ of the freezing front of the backwater surface was only analyzed by the test data of the distance between frozen pipes of $0.8 \mathrm{~m}$. The reason is the same as in Section 3.1. By making derivative frozen time $t$ of $E_{d}, v_{d}$ can be achieved:

$$
v_{d}=\frac{\partial E_{d}}{\partial t}=-\frac{E+C x^{2}}{t^{2}}, \quad t \geq t_{e} .
$$

Figure 10 reveals the variation of $v_{d}$ with frozen time under the condition with the distance between frozen pipes of $0.8 \mathrm{~m}$, the seepage velocity of $1.5 \mathrm{~m} / \mathrm{d}$, and the refrigerant temperature of $-25^{\circ} \mathrm{C}$.

Firstly, when influenced by the flow around the groundwater, the frozen front in the middle of the backwater surface develops faster. Because the groundwater flow velocity at both sides of the backwater surface is faster and the water temperature is higher, the frozen front develops slower than that in the middle. Secondly, the development velocity of the frozen front surface is inversely proportional to the square of the frozen time $t$. At the initial stage after the second row of frozen soil columns overlaps, the frozen front of the backwater surface develops faster, but the decline trend of speed is also faster. With the extension of the freezing time, $v_{d}$ gradually decreases. When the freezing time is long enough, the backwater surface reaches the cold and heat balance, and the frozen front development speed is zero.

In order to facilitate the analysis of the influence of the seepage velocity $u$ and the refrigerant temperature $T_{c}$ on the development velocity of the frozen front surface, let $k=-\left(E+C x^{2}\right)$. Figure 11 shows the effect of the seepage velocity $u$ and the refrigerant temperature $T_{c}$ on $k$.

Figure 11 and formula (6) demonstrated that the influence law of the seepage velocity $u$ and the refrigerant temperature $T_{c}$ on $v_{d}$ is similar to that on $v_{e}$, and $v_{d}$ decreased with the increase of both the seepage velocity $u$ and the refrigerant temperature $T_{c}$.

As mentioned above, the range method was used for calculation and analysis. Table 5 shows the results of the 


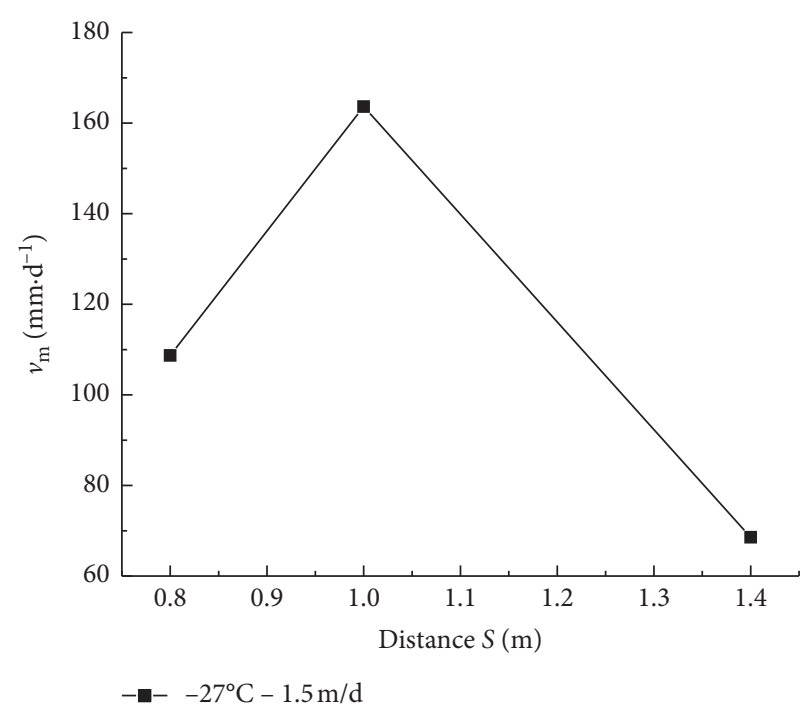

(a)

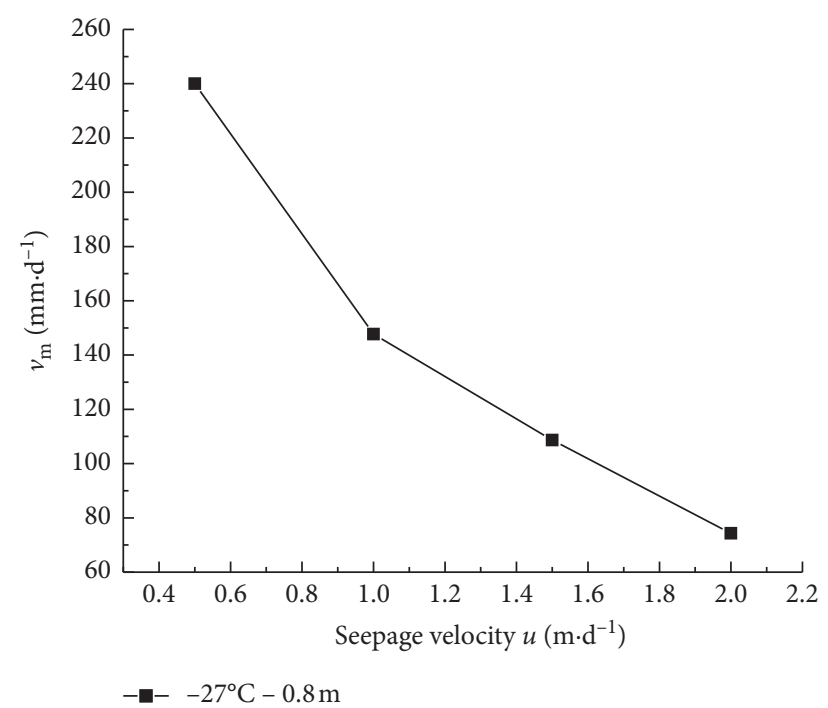

(b)

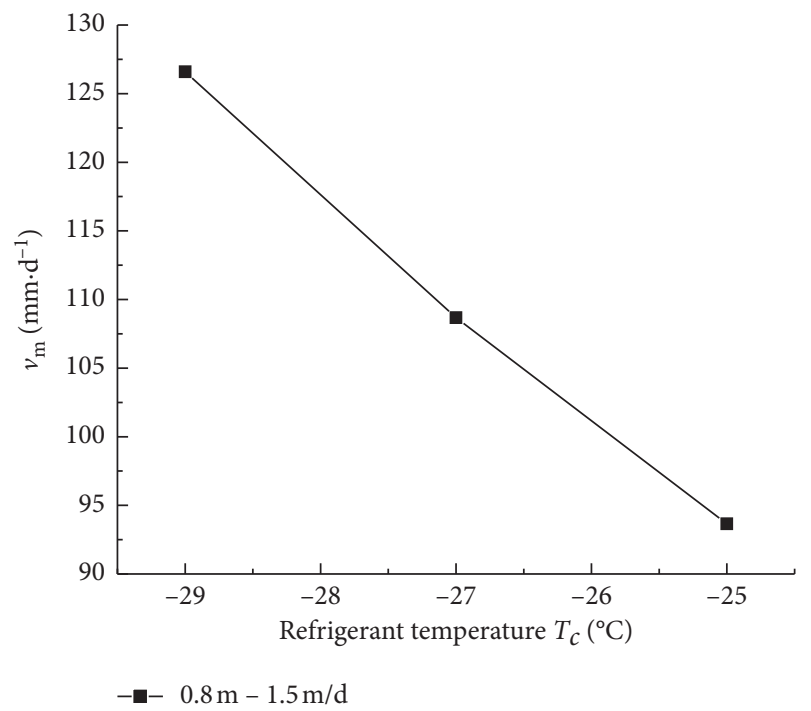

(c)

Figure 9: Influences of various factors on $v_{m}$. (a) Distance between frozen pipes $S$ vs. $v_{m}$. (b) Seepage velocity $u$ vs. $v_{m}$. (c) Refrigerant temperature $T_{c}$ vs. $v_{m}$.

TABLE 4: Calculation of variance of $v_{m}$.

\begin{tabular}{lccc}
\hline & $S$ & $u$ & $T_{\mathrm{c}}$ \\
\hline Range calculation $\left(\mathrm{mm} \cdot \mathrm{d}^{-1}\right)$ & 68.8 & 167.2 & 65.4 \\
\hline
\end{tabular}

range calculation of each factor for $C$ and $E$. The effect of the seepage velocity $u$ on $v_{d}$ was more remarkable than the refrigerant temperature $T_{c}$.

3.5. $t_{s}$. If either upstream $E_{u}$ or downstream lengths $E_{d}$ is ignored, the total freezing formation time $t_{s}$ can be divided into $t_{e}$ and $t_{m}$ according to the time history:

$$
t_{s}=t_{e}+t_{m}=\frac{S}{2 v_{e}}+\frac{E_{m}}{v_{m}} .
$$

In actual engineering, if $t_{s}$ is too long, it can be divided into two cases:

(1) The overlap time $t_{e}$ of the last row of frozen soil columns is too long

(2) The development speed $v_{m}$ is too small, and the extension time $t_{m}$ is too long

The influences of various factors on $t_{e}$ and $v_{m}$ according to the range calculate analysis were obtained in Sections 3.2 and 3.3. The influence of the distance between frozen pipes $S$ and the seepage velocity $u$ on $t_{e}$ and $v_{m}$ is greater than the 


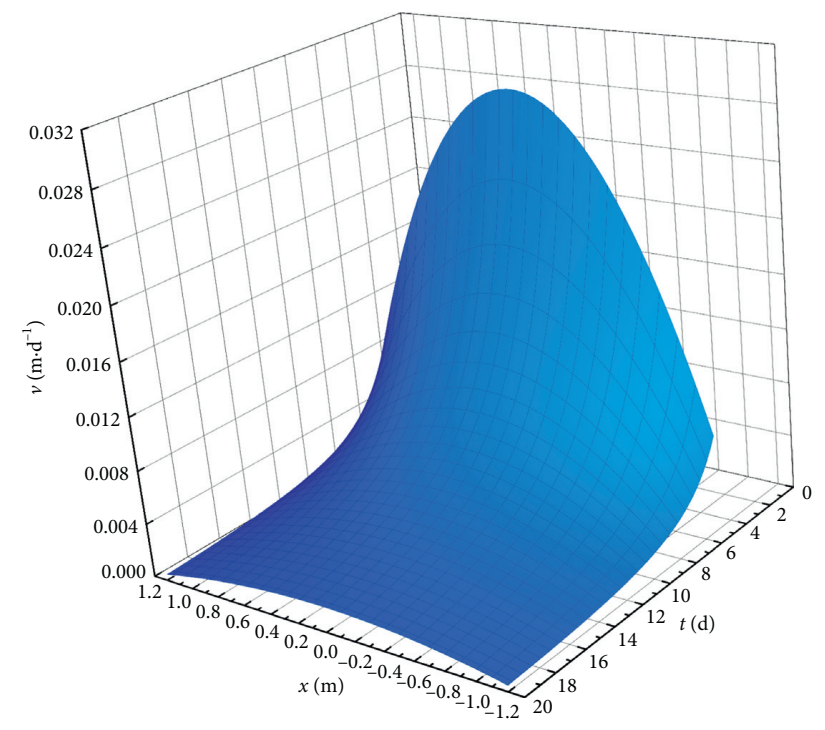

Figure 10: $v_{d}$.

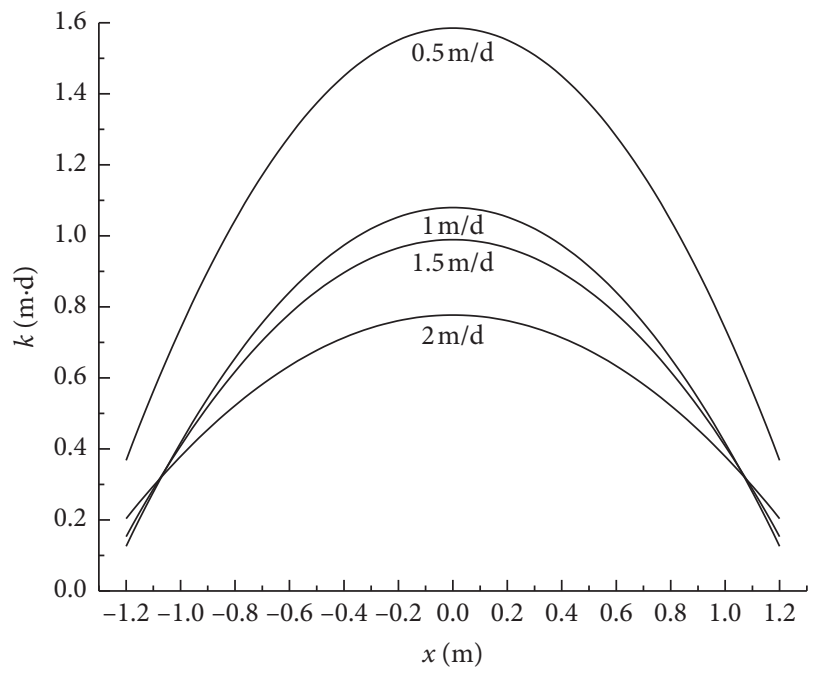

(a)

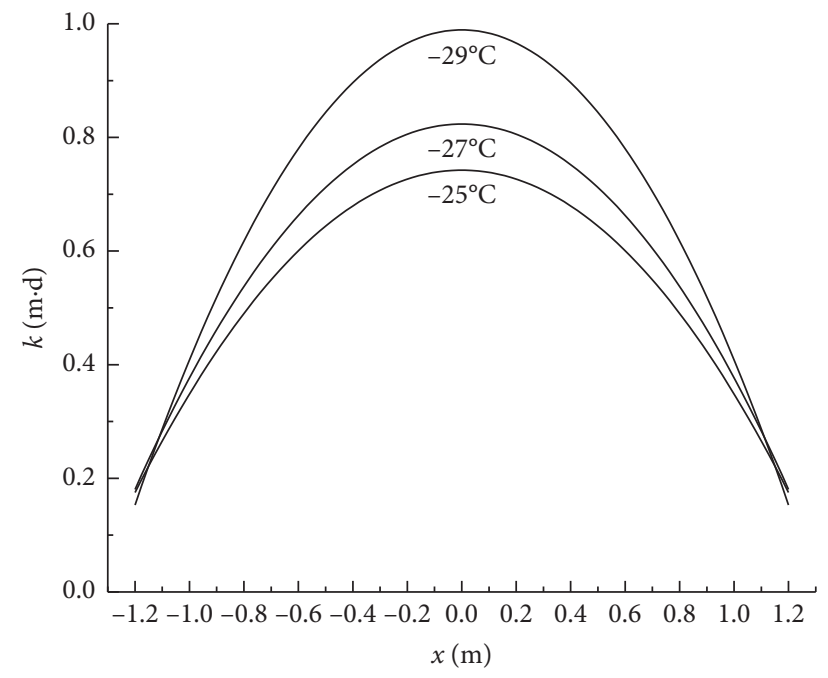

(b)

FIgURE 11: Curves of the effect of various factors on $k$. (a) Seepage velocity $u$ vs. $k$. (b) Refrigerant temperature $T_{c}$ vs. $k$.

TABLE 5: Calculation of variance of $\mathrm{C}$ and $\mathrm{E}$.

\begin{tabular}{lcc}
\hline & Seepage velocity $u$ & Refrigerant temperature $T_{\mathrm{c}}$ \\
\hline$C$ & 0.74 & 0.10 \\
$E$ & 1.16 & 0.32 \\
\hline
\end{tabular}

refrigerant temperature $T_{c}$. The influence of $S$ on $t_{e}$ is greater than $u$, while in the case of $v_{m}$, opposite results were observed that the effect of $S$ is weaker than $u$. Therefore, when result (1) occurs, it is recommended to shorten the distance between the frozen pipes. When result (2) occurs, in order to save the construction cost, it is recommended to use grouting and other measures to reduce the groundwater seepage velocity.

\section{Conclusions}

(1) Under the effect of seepage flow, the backwater surface of the horizontal frozen body in the late stage of freezing is in the shape of quadratic parabolic, and the development velocity of the frozen front surface of the back water surface is inversely proportional to the square of the freezing time. When the length of the water-side surface is fixed, the influence of $u$ on the downstream limit length and the backwater surface development velocity is greater than the $T_{c}$.

(2) The overlap time $t_{e}$ of the second row of frozen soil columns increases with the increase of $S$ and $u$ and decreases with the decrease of $T_{c}$, while the average development velocity $v_{m}$ of the upstream surface 
decreases with the increase of $u$ and increases with the decrease of $T_{c}$, and as $S$ increases first and then decreases. The primary factor to affect $t_{e}$ is $S$, followed by $u$, and finally is $T_{c}$. However, the primary factor to affect $v_{m}$ is $u$, followed by $S$, and finally is $T_{c}$.

(3) Under the experimental conditions of this model, the regression formula between the overlap time of the second row of frozen soil columns and various factors was obtained by regression analysis, and the calculation formula of the maximum arrangement distance of the frozen pipes was obtained. It can provide theoretical basis for the parameter design of large-scale horizontal freezing construction of the Beijing subway.

\section{Data Availability}

The data used to support the findings of this study are included within the article.

\section{Conflicts of Interest}

The authors declare that they have no conflicts of interest.

\section{Acknowledgments}

The research described in this paper was financially supported by the Beijing Science and Technology Commission (Z161100001116088).

\section{References}

[1] A. Marwan, M. Zhou, G. Meschke, and M. Zaki Abdelrehim, "Optimization of artificial ground freezing in tunneling in the presence of seepage flow," Computers and Geotechnics, vol. 75, pp. 112-125, 2016.

[2] Z. Hong and X. Hu, "Application of analytical solution to steady-state temperature field by double-row-pipe freezing and verification with field measurement: a case study of connected aisle," Advances in Civil Engineering, vol. 2019, Article ID 6435060, 12 pages, 2019.

[3] H. L. Jessberger, "Theory and application of ground freezing in civil engineering," Cold Regions Science and Technology, vol. 3, no. 1, pp. 3-27, 1980.

[4] Y. Kim, B. Hwang, and W. Cho, "Development of ground freezing system for undisturbed sampling of granular soils," Advances in Civil Engineering, vol. 2018, Article ID 1541747, 13 pages, 2018.

[5] M. Schultz, M. Gilbert, and H. Hass, "Ground freezingprinciples, applications and practice," Tunnels and Tunneling International, vol. 2008, pp. 39-42, 2008.

[6] X. Zhou, M. Wang, and X. Zhang, "Model test research on the formation of freezing wall in seepage ground," Journal of China Coal Society, vol. 30, pp. 196-201, 2005.

[7] X. D. Hu and T. X. He, "Equivalent-trapezoid method of average temperature calculation for multi-row-pipe straight frozen soil wall," Journal of China Coal Society, vol. 34, no. 11, pp. 1465-1469, 2009.

[8] X. Hu, "Average temperature model of double-row-pipe frozen soil wall by equivalent trapezoid method proceedings," in Proceeedings of the AIP Conference Proceedings, vol. 1233, no. 1, pp. 1333-1338, :Portland, OR, USA, May 2010.
[9] X.-D. Hu, W. Guo, L.-Y. Zhang, J.-T. Wang, and X. Dong, "Mathematical models of steady-state temperature fields produced by multi-piped freezing," Journal of Zhejiang University-Science A, vol. 17, no. 9, pp. 702-723, 2016.

[10] B. Wang, C. Rong, J. Lin et al., "Study on the formation law of the freezing temperature field of freezing shaft sinking under the action of large-flow-rate groundwater," Advances in Materials Science and Engineering, vol. 2019, Article ID 1670820, 20 pages, 2019.

[11] Y.-M. Lai, Z. Wu, Y. Zhu, and L. Zhu, "Nonlinear analysis for the coupled problem of temperature and seepage fields in cold regions tunnels," Cold Regions Science and Technology, vol. 29, no. 1, pp. 89-96, 1999.

[12] P. Yang and A. Pi, "Study on the effects of large groundwater flow velocity on the formation of frozen wall," Chinese Journal OF Geotechnical Engineering, vol. 23, no. 2, pp. 167-171, 2001.

[13] J. Lin, H. Cheng, H. Cai et al., "Effect of seepage velocity on formation of shaft frozen wall in loose aquifer," Advances in Materials Science and Engineering, vol. 2018, Article ID 2307157, 11 pages, 2018.

[14] E. Pimentel, A. Sres, and G. Anagnostou, "Large-scale laboratory tests on artificial ground freezing under seepage-flow conditions," Géotechnique, vol. 62, no. 3, pp. 227-241, 2012.

[15] Z. Li, J. Chen, M. Sugimoto, and H. Ge, "Numerical simulation model of artificial ground freezing for tunneling under seepage flow conditions," Tunnelling and Underground Space Technology, vol. 92, p. 103035, 2019.

[16] J. Hu, W. Liu, Y. Pan, and H. Zeng, "Site measurement and study of vertical freezing wall temperatures of a large-diameter shield tunnel," Advances in Civil Engineering, vol. 2019, Article ID 8231458, 11 pages, 2019.

[17] R. A. Sudisman, M. Osada, and T. Yamabe, "Experimental investigation on effects of water flow to freezing sand around vertically buried freezing pipe," Journal of Cold Regions Engineering, vol. 33, no. 3, Article ID 04019004, 2019.

[18] M. A. Alzoubi, A. Madiseh, F. P. Hassani, and A. P. Sasmito, "Heat transfer analysis in artificial ground freezing under high seepage: validation and heatlines visualization," International Journal of Thermal Sciences, vol. 139, pp. 232-245, 2019.

[19] W. Zhang, B. Wang, and Y. Wang, "Elastic analysis of nonhomogeneous frozen wall under nonaxisymmetric ground stress field and in state of unloading," Advances in Materials Science and Engineering, vol. 2018, Article ID 2391431, 13 pages, 2018. 